\title{
El Salvador en la década de los años 70: Las oportunidades perdidas
}

Héctor Grenni ${ }^{1}$

Recibido en enero 2014 y aceptado en marzo de 2014

\begin{abstract}
Resumen
En este escrito se presentan los procesos políticos y las contradicciones del sistema en El Salvador en la segunda mitad de la década de los años 70. A partir de los fraudes electorales de 1972 y 1977, la agudización de las contradicciones del sistema provocó una intensa efervescencia campesina y urbana que la incapacidad de los gobernantes transformó en la búsqueda de alternativas radicales. En este contexto, la celosa defensa de sus privilegios por parte de oligarquía nacional y la presencia de Estados Unidos condicionaron fuertemente el contexto del fin de la década. De ese modo, el país se acercó irremediablemente hacia la confrontación civil de los años 1980 a 1992.
\end{abstract}

Palabras claves

Fraude electoral de 1972 y 1977, Organización Democrática Nacionalista 'ORDEN', FECCAS, Guardia Nacional, oligarquía, fuerzas armadas de El Salvador.

\begin{abstract}
Political processes and the contradictions of the system in El Salvador in the second half of the decade of 1970 are presented in this paper. Starting from the electoral fraud of 1972 and 1977, the intensification of the contradictions of the system caused intense rural and urban excitement that the inability of the rulers became the search for radical alternatives. In this context, the zealous defense of their privileges by the national oligarchy, and the U.S. presence, strongly conditioned the context by the end of the decade. Thus, the country inevitably moved toward civil confrontation from 1980-1992.
\end{abstract}

Keywords:

Electoral fraud of 1972 and 1977, Nationalist Democratic Organization 'ORDEN', FECCAS, National Guard, oligarchy, armed forces of El Salvador.

1. Director de la Biblioteca de la Universidad Don Bosco. E-mail: hector.grenni@udb.edu.sv 


\section{Las elecciones de 1972 y 1977}

El Salvador de la década de los años 60 vio desarrollarse un proceso de apertura política que generó espacios para la expresión de los descontentos populares y, en general, para la búsqueda de escenarios para el diálogo y la participación. Si bien se trató siempre de espacios limitados y condicionados al respeto de los intereses de la oligarquía, fue suficiente para el comienzo de un intenso proceso de organización de los movimientos populares, largamente esperado. Éstos vieron en esta apertura, por primera vez en la historia, la posibilidad de expresarse.

La siguiente década, sin embargo, vio cerrarse estos espacios que tantas expectativas había generado y abierto tan amplios horizontes. La oligarquía no podía ver con buenos ojos un proceso que llevase al cuestionamiento de sus intereses. Los gobiernos militares, fieles guardianes de los intereses de la oligarquía, dieron marcha atrás en este proceso que ellos mismo habían iniciado. La ya larga serie de amaños de los procesos democráticos -como los fraudes electorales en las elecciones presidenciales de 1972 y 1977 - y de manipulación de los espacios políticos aumentó notablemente, y la represión, ahora selectiva, cobró expresiones inusitadas, como quedó demostrado en la ocupación, en 1972, de la Universidad de El Salvador, la única universidad nacional del país, por las fuerzas de seguridad del estado.

El fin de la frágil bonanza económica de la década de los años 60 , que sólo llegó a una minoría de la población y de lo cual el desmoronamiento del Mercado Común Centroamericano fue sólo una expresión visible, llevó a una creciente efervescencia social. Las huelgas de los trabajadores de la educación agrupados en ANDES, las protestas de un estudiantado universitario que comenzaba a radicalizarse y la proliferación de las organizaciones populares, especialmente entre los campesinos, y su progresiva organización, provocaron la inquietud en la oligarquía, que fue trasladada a los altos mandos del ejército que detentaban el poder político.

Esto llevó a un debate arduo en el seno de los distintos sectores del ejército. En su interior, una tendencia más cercana a las reformas paulatinas que atendiesen las necesidades de las mayorías y fuese capaz de dialogar con la oposición, despertó el rechazo de la oligarquía. Esta tendencia se enfrentó con un sector partidario de hacer frente a la efervescencia popular por medio de la radicalización de la represión. El general José Alberto Medrano representaba a estos últimos, mientras que el coronel Arturo Armando Molina a los primeros. Por primera vez en su historia, las fuerzas armadas reflejaban un profundo debate interno que se traslucía hacia afuera de la institución. La intervención del presidente saliente, general Fidel Sánchez Hernández, que ostentaba el prestigio que le brindaba la corriente de nacionalismo exacerbado por la guerra de 1969 con Honduras, definió la cuestión a favor del coronel Molina. La oligarquía se mostró recelosa ante esta situación. 
Las elecciones presidenciales de 1972 representaban una oportunidad única para los distintos sectores de la oposición: enfrentar al poderoso aparato estatal en un escenario electoral, donde ya se entreveían posibilidades de ganar las elecciones. La Unión Nacional Opositora (UNO) estuvo conformada por partidos políticos estructurados y movimientos de masas, donde confluía una gran diversidad de tendencias políticas que abarcaban un espectro político importante. La UNO estaba conformada por dos movimientos de masas, el Movimiento Nacional Revolucionario (MNR) y la Unión Democrática Nacionalista (UDN); y por dos partidos políticos con una estructura partidaria afianzada. Por un lado, el Partido Comunista Salvadoreño (PCS), que comenzaba un profundo debate interno: un sector dirigente había apoyado al gobierno militar en la guerra contra Honduras, mientras que la disidencia optaba por la lucha armada como único medio para tomar el poder político, desde el cual debería imponerse la revolución social. Por otr parte, el Partido Demócrata Cristiano (PDC), una vez vencida la oposición interna de los grupos conservadores ligados a Napoleón Duarte, reacios a una alianza con el Partido Comunista. Pesaban siempre en el horizonte político las experiencias de Cuba Fidel Castro y de Chile de Salvador Allende.

En 1972 la UNO enfrentó al oficialista Partido de Conciliación Nacional (PCN): por primera vez, el triunfo oficialista no aparecía claro. La oposición se presentaba como una fuerza unificada por primera vez, donde confluían una gran diversidad de tendencias y modos de concebir la cuestión política. El oficialismo, por su parte, contaba con todo el aparato estatal y la presión de la oligarquía, que veía peligrar quizá por primera vez el sistema que protegía sus intereses. El temor oficial se concretó en amenazas, intimidaciones, atentados y agudización de la represión: urnas de plástico transparente, control de las elecciones por parte del ejército y una agresiva campaña en la prensa escrita fueron algunas de las formas de intimidación.

Las elecciones fueron ganadas claramente por la UNO pero el estado llevó a cabo un fraude clamoroso. Hubo protestas generalizadas por parte de los movimientos populares. Un intento de golpe de estado por parte de un sector 'demócrata y joven' de oficiales del ejército no encontró apoyo popular y fue abortado. La reacción de las fuerzas armadas se verificó en un aumento de la represión.

Uno de los protagonistas de esos tiempos califica el fraude como 'fraude burdo y masivo' que debía evitar el fin de la dictadura militar, acelerando un proceso que desembocaría en la cruenta guerra civil. ${ }^{2}$

2. “...comenzó el 20 de enero de 1972, cuando los militares salvadoreños y sus aliados civiles hicieron un fraude burdo y masivo en las elecciones presidenciales de ese año. Mediante ese fraude le robaron las elecciones a dos civiles moderados, Napoleón Duarte y Guillermo Ungo, candidatos a presidente y vicepresidente de la República por la Unión Nacional Opositora (UNO), para evitar que terminara 'el gorilato', como llamábamos a una dictadura presidida por oficiales del ejército que 
Para las fuerzas armadas, las elecciones representaron el comienzo de un profundo debate interno. Por primera vez en su historia se dejaron entrever disensos internos, y por primera vez se replantearon en su seno diversas opciones. Una corriente reformista y democrática fue cobrando cuerpo, si bien todavía no estaba preparada para una demostración de fuerza. Habrá que esperar todavía 8 años, hasta el golpe del año 1979. Por primera vez, también, las fuerzas armadas veían tambalear el sistema que ellas mismas habían contribuido a crear, y en el cual se encontraban cómodas: sabían con precisión cuál era su función.

El año 1972 representó para las fuerzas armadas una oportunidad histórica: tomar partido por las mayorías. Estaban dadas las condiciones para ello: su apoyo a la UNO y la negativa a acompañar el fraude electoral hubieran significado el triunfo de un sistema en el cual no sabían cuál sería su papel, pero que abría grandes expectativas. La presencia en la UNO del Partido Demócrata Cristiano otorgaba visos indiscutibles de legalidad democrática al proceso. Un supuesto apoyo de las fuerzas armadas a la UNO no podría haber sido cuestionado por ninguna de las fuerzas políticas. Sin embargo, su cobardía les impidió tomar partido por un cambio radical del sistema.

La izquierda más radical, que ya en 1972 comenzaba a optar por la vía revolucionaria como la única opción para la transformación del país, vio las propuestas de la UNO como un intento que favorecía a las minorías que detentaban el poder político y económico y, en el fondo, como un intento de 'cambiar algo para que todo siga igual', y tildó de 'adormecedores de conciencias' a quienes lideraban las propuestas y favorecían la vía de las elecciones como forma de llegar al poder, desde el cual se impondría una sociedad sin marginados y un nuevo reparto de la riqueza..

La reacción de las fuerzas armadas se concretó en un aumento de la represión contra los miembros de las fuerzas opositoras para desmantelar su organización. En julio de 1972, el nuevo presidente, coronel Arturo Armando Molina, ordenó la intervención de las fuerzas armadas en la Universidad de El Salvador (UES), con gran despliegue de fuerzas, por ser 'un nido de comunistas': las autoridades llegadas a la UES en 1970, producto de la creciente radicalización estudiantil, habían modificado los programas de formación académica haciéndolos más cercanos a la realidad nacional y a la problemática social. El rector de la UES fue expulsado del país y hubo 800 personas presas.

se extendió por 48 años consecutivos desde 1931. El período de gestación desembocó en la guerra civil salvadoreña el 24 de marzo de 1980, fecha de un magnicidio (de Monseñor Oscar Arnulfo Romero, Arzobispo de San Salvador) que fue un parteaguas en la actitud de muchas personas, y la gota que derramó el vaso de la rabia acumulada en mucho tiempo. Ocho años de gestación, que unidos a los doce de la guerra propiamente dicha, sumieron al país en una honda crisis durante 20 años; es decir, de 1972 a 1992." Mayorga, R., Una propuesta de paz al comienzo de la guerra, en Escobar Galindo, D. et. al., El Salvador, de la guerra civil a la paz negociada, Dirección de Cultura del Ministerio de Relaciones Exteriores, San Salvador, 2011. pág. 9. 
Las fuerzas armadas trataron de rescatar la aparente legitimidad que se les escapaba de las manos con más represión y de manera verticalista y autoritaria. Resurgieron las organizaciones oficiales que operaban en los límites de la legalidad, como ORDEN ${ }^{3}$. Se reclutaron minifundistas, trabajadores agrícolas desempleados y pequeños comerciantes con la promesa de beneficios. Para 'difundir las ideas democráticas' y apoyar al gobierno, se usaron espías, prácticas antidemocráticas, violencia, prebendas, promesas de empleos, destrucción de expedientes judiciales comprometedores... En el imaginario de quienes adherían a esta acción de ORDEN -muchos de ellos no tenían otra opción-, surgió una 'república imaginaria que permitía escapar al desempleo y al hambre, y volcar contra los semejantes la dominación de que eran víctimas. ${ }^{4}$,

Las organizaciones populares vieron cómo se les arrebataba de las manos una posibilidad histórica: la de debatir la situación del país. La única opción, agotada la posibilidad del diálogo electoral, era ahora la radicalización de la oposición, opción que contemplaba la lucha armada como posibilidad cercana. Quedarían, todavía, otras dos oportunidades: las elecciones de 1977 y la que se abriría con el golpe de estado de los ‘militares jóvenes’ en 1979.

El fraude y la represión no lograron la despolitización de la UES, pero sí lograron desarmar la organización de la oposición política. No quedaban ya espacios para el cuestionamiento o el disenso, y la lucha armada se asomaba ya como la única opción posible. Para el Partido Comunista, integrante de la UNO, quedó la convicción de que el ejercicio democrático no era el camino hacia una sociedad más justa: estaban dadas las condiciones para el surgimiento de los grupos guerrilleros. Las Fuerzas Populares de Liberación (FPL) y el Ejercito Revolucionario del Pueblo (ERP) no tardarían en hacer su presentación pública.

La historia de El Salvador está marcada por fechas que marcan puntos de inflexión en su continuidad histórica. El año 1932 fue uno de ellos. El fraude electoral de 1972, que negó a la oposición el triunfo obtenido en las urnas, y la

3. “La Organización Democrática Nacionalista 'ORDEN' es la vanguardia cívica del Pueblo Salvadoreño, una fuerza avanzada que abre camino en la Transformación Nacional. Se inició en noviembre de 1964, como un movimiento de difusión popular de la ideología, la doctrina y los principios y las ventajas del sistema democrático, para contribuir al fortalecimiento de las libertades ciudadanas y al desarrollo de la lucha ideológica contra la penetración y la agresión del comunismo internacional...

El civismo de nuestro movimiento se nutre en el valor básico de la democracia, que consiste en dar a todos mayor oportunidad de desarrollarse plenamente y en establecer un proceso de cambio continuo y ordenado de las estructuras de la sociedad (...)

El corazón de esta base ideológica es el nacionalismo: la fusión del amor a la Patria con la conciencia de nuestra propia nacionalidad. La democracia y el humanismo completan el esquema fundamental de la ideología (...) La ideología es el nervio de nuestra Organización”. Tomado de "Notas sobre la realidad nacional", documento emanado de ORDEN, transcrito a máquina, s/d., 12 páginas, citado por Carlos R. Cabarrús, Génesis de una revolución. Análisis del surgimiento y desarrollo de la organización campesina en El Salvador, Ediciones de la Casa Chata, México, 1984, pág. 259.

4. Gordon, Sara, Crisis política y guerra en El Salvador, Siglo XXI Editores, México, 1989, pág, 143. 
imposición del candidato que daría continuidad al sistema, fue otro momento de inflexión, un 'corte epistemológico en la agudización del conflicto que acabará en la guerra civil: punto de retorno en las esperanzas del bloque social emergente alternativo de conseguir sus aspiraciones por la vía electoral'. ${ }^{5}$

El fraude electoral de 1972 provocó un gran desengaño entre quienes todavía creían en los espacios de participación que ofrecía el sistema, y un profundo desencanto en quienes dirigían los procesos políticos de oposición. En palabras de uno de los protagonistas, Guillermo M. Ungo,

"tratamos año tras año, década tras década, todas las vías posibles; participamos en numerosos eventos electorales, y el resultado fue siempre el mismo: fraudes crecientes con represión y persecución política, restringiendo más y más el poco espacio democrático conquistado". ${ }^{6}$

El año 1972 representó, asimismo, para el régimen, una oportunidad perdida para incorporar a su proyecto de país al bloque opositor, con el cual todavía se podía dialogar, legitimando así un sistema en el cual estaban claros los intereses y los privilegios, y en el cual se podían dar procesos de reformas que fueran, al menos aparentemente, al encuentro de las necesidades de las mayorías y que alejasen la posibilidad de un cambio repentino y violento. ${ }^{7}$

\section{Efervescencia campesina, toma de conciencia y represión}

El contexto salvadoreño de la década de los años 60, 70 y 80 fue uno de los de mayor efervescencia social y política del país en el siglo pasado: un sistema que se agotaba en sí mismo por no encontrar respuestas adecuadas a los reclamos sociales; un poder político que carecía de representatividad y de credibilidad, tanto por su forma de acceder al poder como por su incapacidad para dialogar con los sectores mayoritarios; una institucionalidad cuestionada que debía responder a las presiones de la vieja oligarquía nacional, anteponiéndolos al bien común... En suma, un sistema político incapaz de escuchar las necesidades de las mayorías, y por ende, incapaz de crear los espacios institucionales para ir al encuentro de los cuestionamientos.

5. Gordon, Sara, op.cit., pág, 40.

6. Citado por Roberto Turcios, Una vida por la democracia y la paz, en Escobar Galindo, D. et. al., El Salvador, de la guerra civil a la paz negociada, Dirección de Cultura del Ministerio de Relaciones Exteriores, San Salvador, 2011, pág. 14.

7. Gordon, Sara, o0p.cit., pág. 143. 
Esta incapacidad llevó al gobierno a atender las necesidades expresadas en las manifestaciones populares recurriendo a la represión, la que se manifestó de las formas más variadas: desde la violencia hasta la persecución política, desde la manipulación de los espacios de expresión hasta la distribución selectiva de favores y prebendas.

A medida que se consolidaba la organización de los trabajadores en el campo, se acentuaba el temor de las clases que detentaban el poder económico. Los gobiernos militares se sirvieron de diversas instituciones oficiales para la represión y el control de los campesinos. La existencia de tres cuerpos policiales - la Policía Nacional, la Policía de Hacienda y la Guardia Nacional- permitía este control, ya que dedicaban buena parte de sus esfuerzos a esta tarea.

A ello hay que añadir el trabajo de zapa y de represión realizado por ORDEN, que permitió al gobierno insertarse en las comunidades campesinas. Este cuerpo semi militar estaba conformado por personas imbuidas de un trabajo que concebían como una misión, y que miraban la adhesión a este cuerpo como una oportunidad para salir de la pobreza, ascender en la escala social y ampliar los horizontes. ${ }^{8}$

La represión estatal se dirigió principalmente hacia los dirigentes de las organizaciones populares y las organizaciones armadas. Con frecuencia, también, la represión se dirigió especialmente hacia quienes participaban en las 'reuniones de la palabra', como se llamaba a las reuniones de las Comunidades Eclesiales de Base, y a los militantes de FECCAS; la represión se concretaba en la negativa a darles trabajo o empleos temporarios. ${ }^{9}$

8. El siguiente testimonio de un militante de ORDEN recogido por Sandoval presenta fielmente estas ideas. “...Podemos arrestar a cualquiera que queramos, cualquiera que ande por ahí metiendo idas extrañas en la cabeza de la gente. Aquí en mi cantón yo me siento como un Romero en chiquito. Aquí yo soy la ley". Testimonio recogido por Eric Sandoval en What cannot forgotten, en El Salvador Reports, CAVHRES, vol. II, número 3, Nueva York, diciembre de 1978, página 6. Citado por Robert Armstrong y Janet Shenk en El Salvador. The face of the revolution, Sound and Press, Monthly Review Press, Nueva York, 1991, pág. 1

9. "Sólo a mí no me dan trabajo por motivo de que hace dos años hicimos una huelga y unos orejas me denunciaron y por eso no me dan trabajo. La huelga comenzó en el lote de Jarquín. Éste dio muy grande las tareyas (tareya', por 'tarea', en el léxico popular campesino, el trabajo que puede realizar un jornalero en un día en el área rural) había como diez hombres sacando el sobrante del día anterior. Entonces fui yo y un grupo más y le dijimos a los señores que no trabajaran, que acuerparan el paro y que así lograrían la rebaja en el trabajo. Hubo gente que me mal informó y desde ese tiempo no me dan trabajo. Dijeron que si seguía yendo a la reunión de la Palabra no darían trabajo. Con eso castigaron a toda la colonia. Eso fue el año pasado". Testimonio recogido por Carlos Rafael Cabarrús, op.cit, pág. 81 
Las cifras de asesinatos provocados por las fuerzas de la represión aumentaron drásticamente en la segunda mitad de la década de los años 60, se acentuaron desde los inicios de la década de los años 70 y alcanzaron su culmen en la década siguiente. Los siguientes cuadros, con cifras incompletas ya que han sido tomadas de la prensa escrita y abarcan un período corto de tiempo, muestran con elocuencia la magnitud de la represión.

Asesinatos causados por las fuerzas de la represión gubernamental de enero a junio de 1977.

\begin{tabular}{|l|c|}
\hline \multicolumn{1}{|c|}{ Ejecutores } & TOTAL \\
\hline Fuerzas armadas & 6 \\
\hline Guardia Nacional (GN) & 73 \\
\hline Policía Nacional (PN) & 31 \\
\hline SIC & 4 \\
\hline Policía de Hacienda (PH) & 5 \\
\hline Policía Municipal (PM) & 7 \\
\hline Vigilantes & 4 \\
\hline Organización Democrática Nacionalista (ORDEN) & 8 \\
\hline Combinados & 38 \\
\hline Unión Guerrera Blanca (UGB) & 28 \\
\hline No identificados & 202 \\
\hline TOTAL & 406 \\
\hline
\end{tabular}

Fuente: Elaboración propia a partir de datos tomados de Carlos R. Cabarrús, Génesis de una revolución. Análisis del surgimiento y desarrollo de las organizaciones campesinas en El Salvador, Ediciones de la Casa Chata, México, 1983, pág. 292-293

\section{Víctimas de asesinatos causados por las fuerzas de la represión gubernamental de enero a junio de 1977.}

\begin{tabular}{|l|l|}
\hline \multicolumn{1}{|c|}{ Grupo } & \multicolumn{1}{c|}{ Víctimas } \\
\hline Guerrilleros & 12 \\
\hline Campesinos & 107 \\
\hline Obreros & 61 \\
\hline Sacerdotes & 2 \\
\hline Maestros & 26 \\
\hline Estudiantes & 44 \\
\hline Profesionales & 6 \\
\hline No identificados & 79 \\
\hline Profesión $\mathrm{n} / \mathrm{i}$ & 69 \\
\hline TOTAL & 406 \\
\hline
\end{tabular}

Fuente: Elaboración propia a partir de datos tomados de Carlos R. Cabarrús, Génesis de una revolución. Análisis del surgimiento y desarrollo de las organizaciones campesinas en El Salvador, Ediciones de la Casa Chata, México, 1983, pág. 292-293. 
Posiblemente el intento más serio de ir al encuentro de la efervescencia social que ponía en tela de juicio la legitimidad de un gobierno surgido de un fraude electoral, sin contemplar el uso de la violencia represiva, haya sido la reforma agraria propuesta por el presidente coronel Arturo Armando Molina en 1977, poco antes de dejar el poder.

La reacción de la oligarquía obligó al presidente a retirarla ${ }^{10}$, con lo que el descontento de las mayorías se agudizó, a la vez que ponía en evidencia la sumisión del gobierno militar ante la oligarquía. Este hecho fue agriamente criticado por sectores intelectuales radicados en la Universidad Centroamericana José Simeón Cañas (UCA), administrada por la orden de los jesuitas. Un artículo de Ignacio Ellacuría en una revista de la UCA titulado 'A sus órdenes mi capital', puso en evidencia esta sumisión, a la vez que provocaba el comienzo del distanciamiento de la oligarquía con la Iglesia católica. ${ }^{11}$

El sucesor de Molina, el general Carlos Humberto Romero, llegado al poder también por medio de elecciones fraudulentas, tuvo que hacer frente a la progresiva efervescencia social, a los reclamos cada vez más organizados y a la hostilidad de la oligarquía, que exigía la represión de las manifestaciones populares. La inmensa manifestación popular del 28 de febrero de 1977 en la Plaza Libertad, en la capital San Salvador, que siguió a la noticia de los resultados de las elecciones, terminó en una fuerte represión, con centenares de muertos. ${ }^{12}$ 'En la Plaza Libertad se enterró, para muchos años, cualquier oportunidad de democracia en El Salvador'.

El presidente, legalizado en la presidencia, deslegitimado por el fraude electoral y la represión, se vio cada vez más aislado. Su intento de dar estabilidad a su gobierno por medio de un llamado a la unidad de todos los salvadoreños, al acceder al poder, no tuvo mayores ecos en las organizaciones populares. Solamente un programa de reformas profundas podía tenerlo, y Romero no estaba en condiciones de hacerlo: no contaba con las fuerzas suficientes. ${ }^{13}$

10. "La reforma agraria, uno de los temas favoritos de los comunistas", Chávez Velado, Waldo, Lo que no conté sobre los presidentes militares, Índole Editores, San Salvador, 2006, pág. 176.

11. Cfr. Ignacio Ellacuría, A sus órdenes mi capital, revista Estudios Centroamericanos (ECA), Universidad Centroamericana José Simeón Cañas (UCA), San Salvador, 1977.

12. "Fue poco después de la medianoche, cuando llegaron los miembros de los cuerpos de seguridad y abrieron fuego contra la multitud que estaba concentrada pacíficamente desde hacía varios días, protestando por el fraude electoral. Fueron asesinadas más de 300 personas". Testimonio de Antonio Morales Ehrlich, dirigente demócrata cristiano, sobre la matanza del 28 de febrero de 1977, cuando la multitud había ocupado la Plaza Libertad para protestar por el fraude electoral, citado por Sánchez Cerén, S., La guerra que no quisimos, en Escobar Galindo, D. et. al., op.cit., pág. 37.

13. Gordon, Sara, op.cit., 1989, pág. 219. 
Poco después, el golpe de estado de octubre de 1979 trataría de legitimar el poder y de detener la efervescencia social por medio de reformas radicales que no estaba en condiciones de llevar a cabo: la Junta de Gobierno que surgiría del golpe detentaría el gobierno pero no el poder: ni la oligarquía ni el ejercito estaban decididos a permitir un cuestionamiento del sistema.

La década de los años 70, durante las presidencias del coronel Molina y el general Romero fue de suma agitación social, se decía más arriba. Las organizaciones populares, los sindicatos, los gremios y las organizaciones políticas y campesinas llevaron a cabo una intensa actividad. La mayoría de las huelgas de la década de los años 70 se llevaron a cabo porque los patronos se negaban a cumplir con la reglamentación referida a salarios, horas de trabajo y relaciones laborales; sin embargo, la intervención del gobierno se dirigió, generalmente, a la represión de los huelguistas y no a hacer cumplir las leyes vigentes.

El gobierno del presidente Romero llevó a cabo algunas concesiones tácticas a los movimientos populares: tomó distancia del gobierno anterior, hizo un fuerte llamado a la unidad, levantó el estado de sitio permitiendo mayores libertades de manifestación para las organizaciones populares y propuso una cierta apertura política llamando a colaborar en su gobierno a otras fuerzas políticas.

Sin embargo, la evidente incapacidad del estado para llevar a cabo proyectos que fueran en detrimento de los intereses de la clase dominante y el cierre de la vía electoral como posibilidad de participación política y la represión progresiva, trajeron consigo una mayor radicalización de los movimientos y populares, cada vez más convencidos de que los espacios de diálogo eran muy limitados. Así, el descrédito del gobierno y de las instituciones del estado puso en evidencia que el único camino posible para la resolución de la severa crisis estaba en la oposición declarada. Los movimientos populares se radicalizaron cada vez más: las acciones tomarían, entonces, senderos muy próximos a la violencia. ${ }^{14}$

Así, ya desde los primeros meses de 1977, aún antes de la llegada del general Romero al poder, se realizaron tomas de tierras por parte de campesinos, ante la negativa de los propietarios a arrendarlas, como fijaba la ley. Apoyados por la Federación Cristiana de Campesinos Salvadoreños (FECCAS) y la Unión de Trabajadores del Campo (UTC), con el lema de 'La tierra es para quien la trabaja', y con el fuerte apoyo desde las ciudades de las organizaciones urbanas

14. Gordon, Sara op.cit., pág. 224. 
populares, como el Bloque Popular Revolucionario (BPR), los campesinos sin tierras tomaron muchas tierras incultas. Ello fue acompañado de huelgas y toma de fábricas cuando los propietarios se negaban a dialogar, apoyadas por la Federación Nacional Sindical de Trabajadores Salvadoreños (FENASTRAS). La prensa escrita criticó agriamente estos reclamos y estas tomas. ${ }^{15}$

En esos años, los programas sociales del presidente Romero, que intentaban paliar la efervescencia social, hicieron posible la relación directa y vertical de las fuerzas armadas con algunos sectores populares. Las fuerzas armadas, en cuyo seno comenzaba a abrirse un interesante debate, buscaron adecuar su lugar en la sociedad mediante nuevas relaciones con las organizaciones populares. Encontraron un espacio idóneo para ello en las modificaciones de sus objetivos y en las estructuras organizativas del aparato estatal, en el que comenzaban a incidir ocupando puestos de dirigencia, y presentaban un nuevo modelo de estado, más acorde a las exigencias surgidas. Así, algunos oficiales hicieron carrera asumiendo tareas que, al par que pretendían ir al encuentro de las necesidades populares, aseguraban sus intereses corporativos, fortaleciendo su alianza con el estado.

Este nuevo protagonismo por parte de los altos oficiales de las fuerzas armadas aseguraba lealtades al tiempo que diversificaba intereses. El aparato estatal se llenó de generales y coroneles, incluso en espacios que no respondían a su preparación, como el Banco Central de Reserva, la Compañía Salvadoreña del Café, la Comisión de Energía Eléctrica del Río Lempa (CEL), el Banco de Fomento Agropecuario... Sin embargo, y a pesar de este 'desembarco' de oficiales en las estructuras del estado, tanto éste como la política siguieron bajo el control de la oligarquía. ${ }^{16}$

El fracaso de las tibias reformas puso el gobierno del general Romero en una situación más delicada, si cabe: cuestionado en su legitimidad, era cuestionado ahora en su capacidad para controlar la efervescencia social que se le escapaba de las manos. Ante ello, la promulgación de la Ley de Garantía y Defensa del Orden Público -prácticamente, una declaración de suspensión de las garantías constitucionales-, propuesta por el presidente Romero, aprobada por la Asamblea y con fallo a favor de parte de la Corte Suprema de Justicia, todo ello en un mismo día, fue el último intento de controlar la situación. Con el objetivo de prohibir 'doctrinas anárquicas y contrarias a la democracia', las acciones 'destinadas a implantar y apoyar doctrinas totalitarias' se convertían en delitos: la rebelión, el llamado a la sedición, el acopio de armas, la conspiración, la

15. Por ejemplo, cfr. el editorial del diario La Prensa Gráfica del 6 de diciembre de 1976.

16. Gordon, Sara op.cit., pág. 176. 
participación en reuniones, la propaganda por cualquier medio, las relaciones con personas de organizaciones extranjeras, los actos de omisión de funcionarios o empleados públicos, cualquier acto tendiente a alterar el desarrollo normal de las actividades productivas del país, la destrucción o inutilización de servicios públicos o comunitarios, la participación en organizaciones que sustentasen ideas anárquicas, la propaganda interior, el envío al exterior de noticias que pudieren perturbar la paz pública, la facilitación de locales para ser usados contra la paz pública, la traición, el secuestro o asesinato de funcionarios, el allanamiento masivo de lugares de trabajo...

Para evaluar si los nuevos delitos se efectuaban 'para implantar o apoyar doctrinas totalitarias', la Ley tenía en cuenta la calidad de la persona ofendida: el hecho de ser funcionario público, militar en servicio, miembro de los cuerpos de seguridad o empresario daba garantía de veracidad a la denuncia. Para la decisión de la culpa, la Ley tenía en cuenta la delación, la presunción, el indicio o el 'dominio público'. Los cuerpos de seguridad tenían aquí la herramienta jurídica para actuar contra la oposición y perseguirla. ${ }^{17}$

La Ley permitía a los cuerpos de seguridad actuar para desocupar tierras ocupadas, disolver huelgas, reprimir manifestaciones, evitar la realización de asambleas y actos públicos de oposición, efectuar capturas y ejecutar operaciones contra militantes de organizaciones político-militares. La Ley elevaba la desigualdad jurídica a la categoría de Ley de la Nación y otorgaba a quienes debían hacer cumplir la ley, facultades de intervención en casi todos los órdenes de la vida social. En la práctica, hacía posible el control de las organizaciones populares.

Las arbitrariedades se sucedieron en forma creciente así como los conflictos violentos entre las organizaciones populares y las que respondían al gobierno. ORDEN y FECCAS se enfrentaron con frecuencia, en este contexto, lo que obligó a intervenir al ejército. La dudosa legitimidad de la Ley, la escasa capacidad del estado para aplicarla, las dificultades del gobierno para negociar demandas, la progresiva capacidad organizativa de las organizaciones populares y el creciente descontento popular, hicieron de El Salvador un polvorín que podía estallar en cualquier momento.

La Ley logró controlar las huelgas, pero no otras formas alternativas de oposición, como la desobediencia civil, la toma de rehenes y la ocupación de iglesias y embajadas, que en poco tiempo se convirtieron en noticias cotidianas.

17. Gordon, Sara, op.cit., pág. 236-237. 
Todo ello minaba la imagen del gobierno en el ámbito internacional. En febrero de 1978, huelguistas del ingenio Izalco, reprimidos, ocuparon pacíficamente la catedral de San Salvador, ya cuando Monseñor Romero ocupaba el arzobispado, la iglesia del Calvario, y las embajadas de Costa Rica, Venezuela, Panamá y Suiza, y las oficinas de la ONU. En enero de 1979, en vísperas del viaje del presidente a México, integrantes de organizaciones populares ocuparon la sede de esa embajada, tomando como rehenes a 150 personas, poniendo clamorosamente en tela de juicio la capacidad del gobierno para controlar la situación. Paralelamente, se secuestraba a empresarios extranjeros y las fuerzas guerrilleras ajusticiaban a prominentes cafetaleros o miembros del gobierno.

La violencia que guardaba el sistema desde hacía decenios, estallaba en 'el Pulgarcito de América' con una intensidad inusitada, y la oligarquía no era ajena a ello.

\section{La oligarquía salvadoreña}

En un país tan pequeño como El Salvador, las clases dominantes tienen nombre y apellido, son conocidas, conocidos sus apellidos, sus negocios y sus intereses. ${ }^{18}$ La oligarquía salvadoreña, 'la más voraz de la región centroamericana' y, probablemente, la que tiene mejor definidos sus intereses y sus alianzas, ha actuado ya desde principios del siglo XX con un acentuado espíritu corporativo. Su temprana definición de intereses la ha llevado a demostrar una marcada conciencia de clase. Sus alianzas empresariales se ven reforzadas por alianzas matrimoniales, conformando una clase social en la que es difícil entrar. ${ }^{19}$

La oligarquía criolla de los tiempos de la colonia -urbana, doblemente dependiente de Guatemala y España-, con fuertes intereses en el añil, fue formándose con una acentuada conciencia de clase que, sin abrir por ello los horizontes a la participación de las mayorías en la riqueza, derivó en un sentimiento nacionalista que originó las revueltas de 1811, 1814 y 1821. A partir de 1850, el añil fue sustituido por el café en los negocios de la naciente oligarquía, y ello cambió el panorama económico del país.

18. Ver Colindres, Eduardo, Fundamentos económicos de la burguesía salvadoreña, UCA Editores, San Salvador, 1977. También María Dolores Albiac, Los ricos más ricos de El Salvador, en Cardenal, Rodolfo y González, Luis, (comp.), El Salvador: la transición y sus problemas, UCA Editores, San Salvador, 2007, pág. 153-183.

19. Cfr. el interesantísimo trabajo de Rodolfo Paniagua, La clase empresarial hegemónica salvadoreña, Revista ECA, 1992, Ed. Universidad Centroamericana José Simeón Cañas, San Salvador, 1992. Paniagua plantea que las uniones matrimoniales han consolidado las coincidencias de intereses en la clase hegemónica, de modo que 'tocar' una de las empresas pertenecientes al grupo provocaría la reacción en cadena de las otras. De este modo, si la izquierda llegara al poder político alguna vez en El Salvador, le sería muy difícil gobernar si intentara recortar los privilegios. 
A partir de entonces, el capital nacional y extranjero, que comenzaba a fluir, se concentró en la producción y comercialización del café, cambiando la estructura de la propiedad de la tierra, y el grupo cafetalero se consolidó como grupo hegemónico, con nuevos horizontes y con una nueva presión sobre la tierra agrícola, especialmente sobre los ejidos comunales y las tierras indígenas. Se agravaba así el ya tradicional problema de la subsistencia y del acceso a la tierra para las grandes mayorías marginadas del sistema.

Ya desde la segunda mitad del siglo XIX, los descendientes de los criollos que declararon la independencia y que tenían fuertes intereses en el añil, se apropiaron de las tierras que el estado liberal de ese tiempo puso a disposición, se aliaron con nuevos aportes llegados a principios del siglo XX, principalmente europeos y estadounidenses, $\mathrm{y}$, mediante la explotación sin atenuantes de la abundante mano de obra, crearon una clase social que basó su principal fuente de riqueza en la producción y explotación del café.

El aporte de un núcleo empresarial proveniente del Cercano Oriente, llegado poco después de las primeras décadas del siglo, aportó nuevos capitales que se desarrollaron rápidamente y contribuyeron a diversificar el horizonte empresarial, incursionando en el ramo del comercio y de la industria incipiente.

Se fue conformando de este modo una sociedad con profundas contradicciones y una gran cantidad de personas que participaban sólo tangencialmente en la distribución de las riquezas producidas. Los dueños del capital se apoderaron de las instituciones del estado liberal, manejaron los procesos democráticos según sus intereses y usaron las fuerzas armadas como vigilantes celosos del sistema. ${ }^{20}$

La oligarquía procuró el control del 'cuadrado mágico' de la dominación: el control de la tierra, de la explotación, de la producción y del sistema financiero. ${ }^{21}$ Ello le permitió controlar, no sólo la producción, sino también la economía, el empleo y las relaciones laborales, el destino del crédito y los procesos políticos. Le permitió, a su vez, ejercer una especie de veto sobre los intentos de revisar la propiedad de la tierra y la distribución de la riqueza, y de cuestionar el sistema. Y se adueñó de la distribución de la riqueza, fijando los sueldos a medidas de sus intereses: lo estrictamente necesario para el mantenimiento del sistema.

La propiedad de la tierra, en un país con una altísima densidad de población, le confirió el control de la economía, que usó para afianzarse como clase social con privilegios económicos y políticos. En 1979, 132.500 microfincas tenían 
una extensión de menos de una hectárea cada una y representaban el $5 \%$ del total de la tierra productiva; en el otro extremo, 800 macrofincas con una promedio de 511 hectáreas cada una, representaban más del $28 \%$ de la tierra productiva. ${ }^{22}$

Este panorama se completa con el dispar acceso a los créditos estatales. Las políticas fiscales de los gobiernos militares favorecían en gran medida a los emprendimientos de las clases dominantes, mientras que las clases marginadas, las clases medias y los sectores campesinos, que abarcaban a la inmensa mayoría de la población, sólo participaban en forma minoritaria de las políticas fiscales. En 1974 y 1975, el 64 \% de los créditos hipotecarios fueron a parar al sector de productos de exportación, mientras que sólo el 15\% fue a parar al sector de granos básicos y producción pecuaria ${ }^{23}$.

La inmensa disparidad de posibilidades entre una fuerte oligarquía agraria y una clase campesina sometida y con escasas posibilidades de reacción, puso en evidencia las profundas contradicciones del sistema. A ello se añadió pronto una clase urbana hacinada y desempleada. Ambos sectores, campesinos y marginados urbanos, comenzaron desde principios de la década de los años 60 un proceso de concientización progresiva. La distancia entre unos y otros, privilegiados y desfavorecidos del sistema, hizo posible que los dos polos se unificasen en torno a intereses comunes y reconocidos. Los reclamos de las clases de campesinos y marginados urbanos buscaron afanosamente un diálogo que la oligarquía se rehusó a atender. Los conflictos estaban en la puerta.

El nacimiento de la efervescencia popular de la década de los años 70 efervescencia que el mismo sistema generaba-, encontró a la oligarquía sumida en sus negocios, y ésta decidió enfrentarla con una represión feroz. Podría haber abaratado los precios de los granos básicos y los productos de primera necesidad, y con ello habría atenuado las exigencias y habría dado una vía de escape a la creciente tensión social. Estaba en condiciones de hacerlo porque dominaba todos los resortes de la economía. Sin embargo, su miopía y su voracidad le hicieron seguir las normas del mercado, manteniendo ganancias a cualquier costo social, encareciendo dichos productos y sumiendo a las mayorías marginadas aún más en la miseria y aumentando así la tensión y los brotes revolucionarios. En el fondo, el ambiente de revolución en la década de los años 70 fue provocado, en buena medida, por la oligarquía. En palabras de Cabarrús, 'la miopía capitalista ha permitido el brote revolucionario'. Sin duda, puede decirse que no sólo permitió, sino provocó el brote revolucionario. ${ }^{24}$

22. Datos tomados de Sector Público Agropecuario en El Salvador (SPAG), Ministerio de Agricultura y Ganadería, s/d, (circa 1979).

23. Tomado de Sector Público Agropecuario en El Salvador (SPAG), Ministerio de Agricultura y Ganadería, s/d, (circa 1975)

24. Cabarrús, Carlos Rafael, op.cit, pág. 111. 
Ya desde principios del siglo XX la clase dominante había comenzado a expandir sus negocios, diversificando el destino y el origen de un comercio exterior que dominaba. En las primeras décadas del siglo, los tradicionales destinos europeos del comercio diversificaron sus mercados, ampliando los horizontes de sus negocios. La irrupción de Estados Unidos ${ }^{25}$, que aumentó significativamente su presencia en el país en las tres primeras décadas del siglo, aportó una mayor diversificación y dinamismo al comercio exterior y nuevas exigencias a la producción. La oligarquía vio 'nombres nuevos' entre sus filas, y respondió a estos nuevos incentivos con un mayor dinamismo, adaptando la producción a las nuevas exigencias y acentuando la explotación de una mano de obra barata, abundante y necesitada.

Al mismo tiempo, este dinamismo nuevo le dio mayor autonomía con respecto al quehacer de la sociedad de su tiempo, adquiriendo una fisonomía altanera y proponiendo un nacionalismo forjado al ritmo de sus intereses. El nacionalismo salvadoreño confundió los intereses nacionales con los de las clases privilegiadas. Así, fue naciendo la idea de un país inexistente, 'el país de la sonrisa, con un pueblo trabajador y acogedor'. La dependencia parcial de Estados Unidos en el comercio exterior y la variedad de opciones le hizo adquirir cierta independencia y acentuó su presencia en el sistema.

Al contrario de las demás oligarquías centroamericanas -con excepción, quizá, de las clases dominantes costarricenses-, la oligarquía salvadoreña conservó siempre una cierta independencia y un mayor margen de maniobra y, por ende, de respuestas. ${ }^{26}$

La monolítica unidad de la clase dominante sufrió algunos cambios con el cambio de escenarios productivos, pero éstos no modificaron sus opciones. La apertura del escenario regional y mundial después de la década de los años 60 , y el recambio generacional en la vieja oligarquía salvadoreña hicieron de detonantes. Los hijos de los antiguos integrantes de la oligarquía habían estudiado en universidades de Estados Unidos o en Europa, y trajeron nuevos aires y nuevos horizontes. La vieja y tradicional oligarquía conservadora siguió con sus antiguos intereses, los que habían construido su riqueza; siguió con la apuesta por el proteccionismo, ligada a ORDEN y a la represión y opuesta a cualquier tipo de reforma que implicase la redistribución de la riqueza o el cuestionamiento del sistema. Las nuevas generaciones, sin embargo, traían aires nuevos y estaban abiertas a la industrialización y a la modernización del estado. Siguió incólume, eso sí, la vieja explotación de la mano de obra.

25. Cfr. Grenni, Héctor, Evidencias de la presencia de Estados Unidos en El Salvador en las primeras tres décadas del siglo XX, en Revista Científica 8 y 9, Universidad Don Bosco, San Salvador, 2008 y 2009.

26. Cabarrús, Carlos Rafael, op.cit., pág. 35-36 
Y si bien la oligarquía diversificó sus actividades y sus inversiones, diversificando así sus intereses, la producción siguió estando en las mismas manos. La oligarquía cafetalera y terrateniente fue también algodonera y financiera: al control de las tierras, ahora con nuevas producciones, se sumó el control de la banca, en momentos en que el país comenzaba a 'tercerizar' su producción: controlaba ya las mejores tierras productivas, el procesamiento y la comercialización; ahora controlaba también los bancos.

La voraz oligarquía salvadoreña, celosa defensora de sus privilegios, no permitió que su miopía le dejara ver la oportunidad histórica que se abría a partir de la toma de conciencia de las mayorías marginadas, para compartir la riqueza producida y crear 'una sociedad donde quepan todos', en el decir de Hinkelammert: prefirió retener sus privilegios a toda costa. Exigió a las fuerzas armadas en el gobierno 'dejar de lado los temores y contemplaciones, poner alto al desorden y el crimen' ${ }^{27}$ de los frentes populares y las organizaciones populares urbanas y rurales. Sólidamente representada en la Asociación Nacional de la Empresa Privada (ANEP) ${ }^{28}$, fundada en 1966, y en la Asociación de Beneficiadores y Exportadores de Café (ABECAFE) ${ }^{29}$, creó sus propias organizaciones, algunas de vida efímera, porque respondían a necesidades coyunturales: el Comité de Defensa de la Patria, el Comité de Patriotas Salvadoreños, la Agrupación Pro Defensa de la Libertad... Propaló la idea de que los frentes populares y las organizaciones político-militares tenían una dirección única, y que la tolerancia del gobierno en favor de los derechos humanos favorecía la acción de estas organizaciones, lo que llevaría a la disolución del sistema, exigiendo al gobierno la represión. Los periódicos de su tiempo dedicaron varias páginas a las manifestaciones de estos pequeños grupos defensores de la oligarquía.

Los medios de comunicación, en manos de la oligarquía, impusieron su propio modo de ver la realidad, no fueron capaces -ni estaban interesados en hacerlo- de ofrecer información fidedigna de las contradicciones evidentes ni del conflicto que se veía venir. Optaron por hacer de 'altavoces del discurso oficial', evitando conflictos y asegurando intereses. ${ }^{30}$

\section{La presencia de Estados Unidos}

La presencia de Estados Unidos en América Latina puede rastrearse ya desde principios del siglo XIX. En numerosas ocasiones, esta 'presencia' se transformó en 'intervención'. De hecho, la desmembración de América Central, que

27. Gordon, Sara, op.cit., pág. 227.

28. Cfr. www.anep.org.sv

29. www.consejocafe.org

30. Revista digital Contrapunto, www.contrapunto.com.sv/especiales/analisis-historia-de-laguerra-mucho-por-conocer, consultado el 20.02.2012. 
conformaba una unidad administrativa en los tiempos de la colonia, aseguraba en cierto modo la frontera sur de Estados Unidos, aún antes de la ocupación de Texas. Por otro lado, la región ofrecía interesantes matices geoestratégicos ante la posibilidad, finalmente concretada en Panamá, de la realización de una comunicación entre los océanos Atlántico y Pacífico. Ello llevó a Estados Unidos a la consideración de los asuntos centroamericanos como asuntos de interés nacional.

La dinámica política de la región centroamericana, unida a la acentuada dependencia externa de los países que la conforman, constituyó un área de gran volatilidad: los problemas sociales se unieron a la extrema dependencia del contexto internacional: los países centroamericanos se constituyeron en lugares de concreción de los intereses más variados. El protagonismo regional fue variando con los vaivenes políticos: la Honduras de la United Fruit Company cedió el protagonismo a la Guatemala de Jacobo Arbenz, que lo cedió a Nicaragua en los tiempos de la revolución sandinista; en la década de los años 80 , El Salvador ocupaba un lugar importante en la agenda política de la región. ${ }^{31}$

A lo largo del siglo XX, una larga lista de intervenciones y presencias estadounidenses marcaron la Historia de la región: la presencia de los soldados ('marines') estadounidenses en Nicaragua en 1933, a lo que siguió la imposición de los Somoza y la creación de la Guardia Nacional; el silencio y la aquiescencia de la política de Estados Unidos ante el recurso militar para la sucesión en el poder político en El Salvador, en 1931, 1948, 1960 y 1972, en algunos casos, incluso, con evidentes violaciones de los procesos democráticos; la intervención evidente en el derrocamiento de J. Arbenz en Guatemala; el papel de la United Fruit Company en Honduras... ${ }^{32}$ son sólo algunas muestras de las numerosas intervenciones de Estados Unidos en la región. ${ }^{33}$

Tanto el Caribe como América Central fueron convirtiéndose, paulatinamente, en zonas de importancia crítica. La amenaza latente por parte del bloque liderado por la Unión Soviética en una región que la guerra fría había reservado para la influencia de Estados Unidos obligaba a intensificar su presencia, ante el peligro de ver 'partido en dos' el continente, amenazando por el sur y por el norte a México y Venezuela, los dos grandes productores de petróleo, y extendiendo la amenaza al canal de Panamá. ${ }^{34}$

31. “...el futuro de Centroamérica dependerá en gran parte de lo que suceda en El Salvador...”, en Shultz, G., George, El enfoque de Estados Unidos respecto a los problemas en la cuenca del Caribe, citado por Bitar, S. y Moneti, C., Política económica de Estados Unidos en América Latina (Documentos de la Administración Reagan), grupo Editor Latinoamericano, Buenos Aires, 1984, pág. 145.

32. Montobbio, M., op.cit., pág. 83.

33. Para una muestra de la creciente presencia de Estados Unidos en El Salvador, cfr., Hector Grenni, op.cit.

34. Nixon, Richard, La verdadera guerra, Ediciones Nacionales del Círculo de Lectores, Bogotá, 1981, citado por Figueroa Salazar, A., El Salvador. Elementos de su historia y sus luchas (1932-1985), Fondo Editorial Tropycos, Caracas, 1987, pág. 111. 
El conflicto salvadoreño, originado en las profundas contradicciones internas, no escapaba a los condicionamientos del contexto internacional: Estados Unidos miró el conflicto salvadoreño como parte de un contexto regional que amenazaba su seguridad nacional desde su 'frontera sur'. ${ }^{35}$ Con una larga tradición de presencia privilegiada en la zona, para Estados Unidos se convirtió en un escenario más de los muchos en los que se desarrollaba el conflicto EsteOeste. En función de ello, el país del norte intentó darle al conflicto interno salvadoreño un matiz cercano al de 'guerra de baja intensidad'. Centroamérica fue convirtiéndose, de este modo, en una región de gran importancia estratégica para la política exterior de Estados Unidos. ${ }^{36}$

La preocupación estadounidense, celosa de la intervención extraña en su 'patio trasero', imaginó al Caribe convertido en 'un lago marxista-leninista', ${ }^{37}$ y la amenaza a los intereses de las oligarquías locales en amenazas a sus propios intereses.

Entre los años 1918 y 1940, entre las dos guerras mundiales, el país del norte intensificó su presencia y su influencia en El Salvador. La intensificación de los flujos comerciales, el registro de patentes y marcas estadounidenses, la intensificación del tráfico de barcos en los puertos salvadoreños y la instalación de empresas marcan la agudización de esta presencia, que tomará características políticas y militares. ${ }^{38}$ Por ello, buscó frenar la 'amenaza marxista' proveniente de las insatisfacciones locales apoyando reformas que atenuasen las contradicciones.

Pronto los militares salvadoreños vieron en la alianza con Estados Unidos la oportunidad de un crecimiento profesional que les aseguraba un lugar privilegiado en la sociedad salvadoreña y el respeto de la oligarquía, y buscaron en los programas estadounidenses la confirmación de un aprecio que las mayorías en el país le negaban: los militares salvadoreños buscaron afuera del país una legitimación que difícilmente lograban adentro de él. Así, adhirieron a los programas de formación militar ofrecidos por Estados Unidos. ${ }^{39}$

35. Montobbio, M., op.cit., pág. 61.

36. El historiador estadounidense George Shultz sostiene que se trataba de "una región que tiene importancia crucial e inmediata para nuestros intereses nacionales. Basta mirar un mapa para advertir que constituye nuestra tercera frontera. Si esta región es dominada por regímenes que nos son hostiles o si se convierte en escenario de perturbaciones sociales prolongadas, el impacto que ello tendría sobre nuestra economía y vida social seria de grandes proporciones". Shultz, George, El enfoque de Estados Unidos respecto a los problemas en la cuenca del Caribe, en Bitar, Sergio y Moneti, Carlos J., Política económica de Estados Unidos en América Latina (Documentos de la Administración Reagan), Grupo Editorial Latinoamericano, Buenos Aires, 1984., pág. 360.

37. Montobbio, M., op.cit., pág. 89.

38. Figueroa Salazar, A., Figueroa Salazar, Amílcar, El Salvador. Elementos de su historia y sus luchas (1932-1985), Fondo Editorial Tropykos, Caracas, 1987, pág. 108-109.

39. “La administración del Presidente Jimmy Carter confirmó hoy que está entrenando a oficiales salvadoreños en una escuela militar en Panamá con el objeto de prepararles en una lucha antisubversiva desprovista de crueldad... El portavoz John Trattner dijo que el programa se titula 'El aspecto de los derechos humanos en el desarrollo de la defensa externa'”, en 'La Casa Blanca admitió entrenamiento de oficiales salvadoreños en Panamá’, periódico El Nacional, $n^{\circ} 13.336$, Caracas, 10.10.1980, pág. 2-A, citado por Figueroa Salazar, A., op. cit., pág. 110. 
Las relaciones con Estados Unidos sufrieron los vaivenes de los intereses del país del norte. Así, a las necesidades locales se unieron las necesidades que dictaba la coyuntura internacional en el contexto de la guerra fría. En 1977, por ejemplo, la bonanza entre el gobierno militar y Estados Unidos se rompió por un informe sobre los derechos humanos en El Salvador que incluía la represión en la Plaza Libertad en San Salvador, la mención del fraude electoral de ese año y la campaña de difamación emprendida por la oligarquía en los medios de comunicación contra los sacerdotes jesuitas. Todo ello implicó la reducción de la ayuda milita por un breve período de tiempo. ${ }^{40}$

En febrero de 1979, meses antes del golpe de octubre, sólo las presiones estadounidenses lograron evitar un golpe de estado por parte de las fuerzas armadas, ante la reacción de la oligarquía ocasionada por las reformas del gobierno del general Romero, que buscaba salir de su aislamiento; las reformas proponían expropiar los grandes establecimientos rurales y nacionalizar los bancos privados.

La decisión de intervenir directamente en las crisis internas de un país pequeño como El Salvador, habla claramente de la importancia estratégica que éste había cobrado. Refleja, asimismo, la preocupación por la efervescencia social, la escalada de violencia y, sobre todo, el temor a una guerra civil, que podría llevar a la toma del poder político por las fuerzas de izquierda. Ello, en el año de la llegada del sandinismo al poder en la vecina Nicaragua ponía en serio peligro la 'frontera sur' de Estados Unidos. El apoyo a medidas tan radicales como las enunciadas pone en evidencia este temor y esta preocupación. ${ }^{41} \mathrm{El}$ Salvador se transformaba en un país de una gran importancia geoestratégica.

La llegada del sandinismo al poder abrió un horizonte lleno de esperanzas para el país limítrofe con la patria de Romero. Precisamente, el arzobispo de San Salvador mencionó esta situación al comenzar la homilía de su misa de domingo, celebrada en la plaza principal de la ciudad el 22 de julio de 1979, lo que causó gran conmoción en las fuerzas armadas del país y especialmente en la oligarquía, que no dejaba de mirar con temor la llegada 'comunismo a la región'. ${ }^{42}$

40. Gordon, Sara op.cit., pág. 21

41. Ridding, Alan, La presión de Estados Unidos bloqueó golpe derechista en El Salvador, periódico El Nacional $n^{\circ}$ 13.130, Caracas, 13.03.80, pág. A-7, citado por Figueroa Salazar, A., op.cit., pág. 109-110.

42. "Yo creo que interpreto el sentir de todos ustedes si nuestro primer saludo de esta mañana es para nuestra hermana república de Nicaragua. ¡ La saludo con sentido de oración fraternal y de solidaridad porque hoy, más que nunca, necesita nuestro apoyo espiritual! La alegría que nos da el inicio de su liberación nos hace también preocuparnos para que ese alborear de libertad no vaya a ser una frustración, sino que el Señor, que ha sido bondadoso, siga siendo la inspiración de ese pueblo nicaragüense. Necesita, también, en esa inspiración cristina, tener en cuenta lo costoso de este momento. Más de 25.000 muertos no son un juguete para desperdiciar un regalo de Dios ofreciéndose en este momento". Tomado de Mons. Oscar A. Romero. Su pensamiento, Tomo VII, Ed. Librería del arzobispado, San Salvador, 2000, homilía del 22.07.79. 
La política estadounidense en El Salvador sufrió los vaivenes de la coyuntura internacional. Dos etapas se pueden diferenciar en este aspecto, separadas ambas por el golpe de estado de octubre de 1979. Durante la presidencia de J. Carter, el régimen salvadoreño fue objeto de una política basada en el respeto a los derechos humanos y la democratización, por parte de Estados Unidos. Por ello, el fraude electoral de 1977 implicó un rápido recorte de la ayuda militar. Después del golpe de estado, en cambio, Estados Unidos impulsó una política de reformas sociales y cambios controlados como alternativa al cambio revolucionario, lo que incluía una reforma del estado. Ésta última pasaba por el apoyo a los programas moderados, la legitimación del orden político, la transformación del ejército en un instrumento eficaz de lucha contra las propuestas radicales revolucionarias y la imposición de un programa de reformas económicas que pudiesen sustraer la base social de las organizaciones revolucionarias. ${ }^{43}$

El golpe de estado de 1979 se adapta perfectamente a esta política.

\section{El contexto regional y nacional a fines de la década de los años 70}

En julio de 1979 el sandinismo llegó al poder en Nicaragua. Con ello, los militantes de las organizaciones populares y la guerrilla alimentaron su imaginario colectivo con la proximidad de la sociedad socialista salvadoreña, 'una nueva Nicaragua', porque 'Si Nicaragua triunfó, El Salvador triunfará'. La oligarquía vio agrandarse sus temores y recelos, mientras el gobierno resucitaba su tesis del 'complot comunista internacional' y trataba de atenuar la efervescencia popular con concesiones que nadie atendía.

En el contexto nacional, el gobierno del general Carlos Humberto Romero tuvo que cargar con un profundo descontento popular y un también profundo descrédito institucional. El primero, por la crisis social que provocaban las necesidades insatisfechas, la estrechez de horizontes y el cierre de los espacios de participación, que derivaban en una creciente organización popular. El segundo, provocado por la incapacidad institucional de dar respuesta a los cuestionamientos, por la dudosa legitimidad de un gobierno nacido de elecciones abiertamente fraudulentas y por el uso indiscriminado de la violencia represiva.

Este contexto redujo los márgenes de maniobra del gobierno, que perdió toda iniciativa, cediéndolos a las organizaciones populares y a la naciente guerrilla armada y acentuando su aislamiento internacional. Al tiempo que arreciaba la represión, el presidente se enmarcó sin mucho margen en una política de defensa de los derechos humanos que nadie creía. El descrédito lo llevó a buscar

43. Montobbio, M., op.cit., pág. 108-109. 
fuera de las fronteras una legitimidad de la que carecía: en 1979 mandaba una representación a la Convención Interamericana de Derechos Humanos que se reunía en Costa Rica, firmaba la resolución de la Organización de los Estados Americanos (OEA) que definía la tortura como un acto contra los derechos humanos y viajaba a México en el mismo momento que las organizaciones populares tomaban la embajada de ese país.

En un intento por poner freno, precisamente, a esa violencia, el presidente promovió un diálogo nacional en el que invitaba a participar a la oposición: el Foro Nacional, 'para realizar un auténtico proceso de participación ciudadana en el hacer político nacional...' ${ }^{44}$ advirtiendo, al mismo tiempo, que no dejaría de lado la lucha contra el terrorismo y la subversión. El presidente invitaba a un diálogo que debía promover la participación ciudadana sin dejar de lado la represión... La invitación estaba viciada desde el comienzo, no tenía objetivos claros, no incluía a todas las fuerzas de oposición y estaba acompañada de una política autoritaria y represiva: la invitación no invitaba a la credibilidad. El Foro, destinado al fracaso, acentuó el descrédito del gobierno. Por otra parte, las organizaciones populares de oposición temían perder la iniciativa política conquistada y se negaron a participar.

El Foro que debía fomentar la participación ciudadana se inició en un clima de violencia: en esos días, las FPL asesinaron al Ministro de Educación, las organizaciones populares ocuparon varias embajadas y el gobierno impuso el estado de sitio implantando tribunales militares para juzgar acciones 'contra la seguridad del estado'. Los representantes del Colegio Médico se retiraron del Foro 'por no encontrar un ambiente propicio a la libertad'. La ruptura de una institucionalidad ya de por sí cuestionada se dejaba entrever en el horizonte político.

Como respuesta al Foro Nacional, las organizaciones de oposición promovieron el Foro Popular, en setiembre de 1979, pocas semanas antes del golpe de estado del 15 de octubre. Este Foro contó con la participación de todas las organizaciones populares: el Partido Demócrata Cristiano (PDC), la Unión Democrática Nacionalista (UDN) y el Movimiento Nacional Revolucionario (MNR), todos ellos de oposición al gobierno, aunque en diversa medida. Este Foro concluyó con propuestas que iban al encuentro de las necesidades de las mayorías: cese de la represión, disolución de las instituciones represivas como ORDEN y UGB, libertad de organización y de expresión, mejoras salariales y acceso de los campesinos al uso de la tierra: una verdadera reforma del estado.

La militancia en las organizaciones populares o en la guerrilla se transformó en una opción válida para quienes miraban críticamente el desarrollo de los

44. Gordon, Sara, op.cit., pág. 262. 
procesos sociales. Los estudiantes, los trabajadores urbanos y los campesinos, militantes de las organizaciones populares transformaron las manifestaciones y reclamos en cuestiones cotidianas y multitudinarias. ${ }^{45} \mathrm{El}$ gobierno perdió toda iniciativa, la oligarquía miraba con un temor creciente los sucesos y el ejército buscaba tímidamente una renovación que no alcanzaba nunca a concretar. Mientras, la Iglesia católica aceleraba su proceso de renovación que la llevaría a las divisiones internas más profundas de su historia.

Fueron los tiempos de mayor efervescencia popular: los tiempos de las grandes manifestaciones y de huelgas masivas con gran aceptación popular. ${ }^{46}$ Fueron, también, los tiempos de la represión selectiva, dirigida contra los dirigentes de las organizaciones populares y los sacerdotes de las comunidades eclesiales de base: se asesinaba a los sacerdotes Rafael Palacios y Alirio Macías, se cometían atropellos contra los dirigentes de las organizaciones populares, se atentaba contra los medios de comunicación del arzobispado y de la oposición, se incentivaba la propaganda contra Monseñor Romero y los jesuitas, aumentaba el número de 'desaparecidos'.

Hacia fines de la década de los años 70 en El Salvador la historia 'se aceleraba' y el tiempo de la revolución parecía inminente. El gobierno del presidente Romero buscó ampliar su base de aceptación levantando el estado de sitio, aumentando los sueldos de los empleados públicos y autorizando el regreso de los refugiados políticos. Al mismo tiempo, anunciaba cambios económicos y amenazaba con 'neutralizar todo foco de perturbaciones que amenacen desestabilizar nuestras instituciones republicanas...' . ${ }^{47}$

Las fuerzas armadas, por su parte, por primera vez en su historia iniciaban un amplio debate interno. Un sector conservador, ligado a viejos esquemas, propiciaba la eliminación física de toda oposición, coincidiendo con el sector

45. “...teníamos la impresión de de ser arrastrados por una gran ola de la historia, actuando cada quien según sus propias motivaciones pero contribuyendo en conjunto a generar una especie de tragedia griega colectiva, donde la dirección de los acontecimientos era dada por fuerzas muy superiores a cualquier individuo." Román Mayorga, Una propuesta de paz al comienzo de la guerra, en Escobar Galindo, D. et. al., op.cit., pág. 10.

46. "San Salvador era una ciudad donde se respiraba la conspiración. Estábamos a principios de 1980. Todos los días habían (sic) marchas y tomas de ministerios. Habían gigantescas organizaciones de masas, el Bloque Popular Revolucionario, el FAPU, las Ligas Populares 28 de Febrero, existía la Coordinadora Revolucionaria de Masas. Todo mundo (sic) estaba organizado en una de las cinco organizaciones político-militares o era simpatizante. Mucha gente andaba armada.

Se utilizaban pseudónimos. San Salvador era un hervidero de rebeldía. Había un entusiasmo, una confianza, la convicción que la huelga general y la insurrección iban a hacer colapsar a la dictadura militar. A partir del asesinato de Monseñor Romero en marzo del 80 todo esto se modifica y se crean las condiciones para una lucha larga, que duró doce años y que se desarrolló fundamentalmente en las zonas rurales, en Morazán y Chalatenango." Rafael Menjívar Ochoa, Tiempos de locura: El Salvador 1979-1981, Índole Editores-FLACSO El Salvador, San Salvador, $5^{a}$ ed., 2008, pág. 127. 47. La Prensa Gráfica, Discurso del presidente Carlos Humberto Romero del 16.08.1979, 17.08.1979, pág. 1-2. 
más radical de la oligarquía. Un sector moderado, formado por oficiales formados en Estados Unidos y defensores de la Doctrina de la Seguridad Nacional, preconizaba reformas parciales controladas verticalmente y la represión con dureza de los movimientos reivindicativos y las agrupaciones populares ilegales independientes; sus integrantes provenían de la Guardia Nacional y coincidían con el sector 'modernizante' de la oligarquía. Por último, un sector 'constitucionalista', formado en México, compuesto por oficiales jóvenes descontentos con los métodos utilizados para la represión, buscaba aplicar reformas que atendiesen a los reclamos de la oposición.

El Partido Demócrata Cristiano de El Salvador apoyó decididamente estas opciones, volcándose totalmente hacia las propuestas de quienes protagonizaron el golpe de estado de octubre de 1979, especialmente después de la proclama de las Fuerzas Armadas que justificaba el fin de una institucionalidad de dudosa procedencia, y proponiendo reformas radicales y profundas: reforma agraria y nacionalización de la banca y del comercio exterior... Sin duda, la oligarquía salvadoreña no podía mirar con buenos ojos un partido político que pudiese cuestionar sus intereses. La Democracia Cristiana veía que las propuestas de la proclama coincidían con sus principios: la búsqueda de la justicia social por medio de la realización de un orden nuevo inspirado en la justicia social, participación en la distribución de la riqueza generada, nacionalismo moderado...

La política estadounidense, siempre presente, miraba con escepticismo la capacidad del gobierno del general Romero para abrir consensos y para ir al encuentro de las necesidades de las mayorías aceptando 'el disentimiento y las demandas de cambio’ para calmar la efervescencia popular que podría derivar en revoluciones al estilo de la vecina Nicaragua. Al principio, alentaron las reformas, pero, al advertir que el gobierno no controlaba la efervescencia social, buscaron un cese anticipado del proceso político, adelantando la salida del presidente. En ese intento, buscaron en el 'sector constitucionalista' del ejército quien pudiese llevar a cabo ese paso, desalentando a los conservadores partidarios de medidas represivas radicales. El golpe de octubre de 1979 fue, en gran medida, propiciado por Estados Unidos. ${ }^{48}$

Se hablaba más arriba del 'quiebre' que significaba el golpe de estado de octubre de 1979, que podría asemejarse a los 'quiebres' de los años 1932 o 1972, como uno de los momentos más importantes de la historia salvadoreña del siglo XX. ${ }^{49}$

48. Gordon, Sara, op.cit.,pág. 268-282.

49. Según uno de sus protagonistas, "Ocurrió cuando era imposible no solo negar la crisis del modelo instaurado en 1932... sino también cuando el país se veía ante una encrucijada fatal, precisamente, a partir de dicha crisis: el estallido de una guerra civil de consecuencias que solo ahora podemos medir o el intento de instaurar un modelo democrático inédito en el país...". Guerra y Guerra, R., Un golpe al amanecer. La verdadera historia de la proclama del 15 de octubre de 1979, Índole Editores, San Salvador, 2009, pág. 14. 
Es necesario volver unos años atrás para aclarar algunas circunstancias del golpe de estado del 15 de octubre de 1979. En 1977 asumió la presidencia del país el general Carlos Humberto Romero. Éste, ante la efervescencia general y el descontento generalizado y público para con un gobierno surgido de elecciones fraudulentas y con la aquiescencia de la oligarquía y los sectores militares tradicionales, no supo ver la oportunidad que se abría para tomar la iniciativa de un diálogo abierto y sincero, que ofreciese espacios para la participación sin marginaciones. Prefirió mantener la vieja alianza de los militares con los intereses de la oligarquía. Su gobierno, basado en el 'Plan Bienestar para Todos', favoreció la sanción de la Ley para la Defensa y Garantía del Orden Público, que daba rienda libre a las fuerzas controladas por el estado para llevar a cabo la represión contra las organizaciones populares. Aumentaron, así, las violaciones a los derechos de las personas, el accionar de los 'escuadrones de la muerte' y de ORDEN.

Ello provocó la respuesta de las organizaciones de campesinos, estudiantes y obreros: hubo tomas de tierras para exigir el derecho a poseer la tierra que se trabajaba; y de fábricas, como la cervecera La Constancia, para exigir aumento de salarios; y manifestaciones de los pobladores de los tugurios, para exigir terrenos para la construcción de viviendas y tomas de embajadas ${ }^{50}$. Asimismo, provocaron manifestaciones los estudiantes, los comerciantes callejeros y las mujeres. Todo esto llevó a un creciente clima de efervescencia popular y de inestabilidad política. En estas circunstancias, el arzobispo Romero había optado por tomar partido por la defensa de los derechos de las personas, denunciando públicamente los atropellos en sus discursos, en sus homilías en las misas y en sus entrevistas con medios de prensa. ${ }^{51}$

La llegada al poder político por parte del Frente Sandinista para la Liberación Nacional en la vecina Nicaragua, junto a la cercanía geográfica e ideológica de Cuba, ponía el conflicto en un horizonte mucho más amplio: el de la guerra fría. Ello incentivó la conformación de diversos grupos políticos de oposición y de organizaciones armadas, que ya comenzaban a salir a 'vida pública', presentando un nuevo elemento con el que había que contar desde entonces y cada vez más: la guerrilla.

En este clima de efervescencia política y social tuvo lugar el golpe de estado del 15 de octubre de 1979.

50. El 5 de mayo de 1979, por ejemplo, miembros del Bloque Popular Revolucionario (BPR) tomaron las embajadas de Costa Rica, Francia y Venezuela y la catedral de San Salvador. Las fuerzas armadas reprimieron a los manifestantes en las afueras de la catedral con un saldo de 15 muertos.

51. "Monseñor Romero apoya y defiende los derechos de los pobres, sus homilías en Catedral son reconocidas como la voz de los sin voz". Sobrino, Martín-Baró, Cardenal, La voz de los sin voz, UCA Ed., 1999, pág. 44. 